\title{
Characterization of Resistance Mechanisms to Powdery Mildew (Erysiphe betae) in Beet (Beta vulgaris)
}

\author{
Mónica Fernández-Aparicio, Elena Prats, Amero A. Emeran, and Diego Rubiales
}

First, second, and fourth authors: CSIC, Institute of Sustainable Agriculture, Apdo. 4084, E-14080 Córdoba, Spain; and third author: Department of Agricultural Botany, Faculty of Agriculture, Kafr El-Sheikh University, 33516 Kafr El-Sheikh, Egypt. Accepted for publication 24 October 2008.

\section{ABSTRACT}

Fernández-Aparicio, M., Prats, E., Emeran, A. A., and Rubiales, D. 2009. Characterization of resistance mechanisms to powdery mildew (Erysiphe betae) in beet (Beta vulgaris). Phytopathology 99:385-389.

Beet powdery mildew incited by Erysiphe betae is a serious foliar fungal disease of worldwide distribution causing losses of up to $30 \%$. In the present work, we searched for resistance in a germplasm collection of 184 genotypes of Beta vulgaris including fodder (51 genotypes), garden (60 genotypes), leaf (51 genotypes), and sugar ( 22 genotypes) beet types. Resistant genotypes were identified in the four beet types under study. In addition, mechanisms underlying resistance were dissected through histo- logical studies. These revealed different resistance mechanisms acting at different fungal developmental stages, i.e., penetration resistance, early and late cell death, or posthaustorial resistance. Most genotypes were able to hamper fungal development at several stages. The later are interesting for breeding aiming to resistance durability. Furthermore, characterization of defense mechanisms will be useful for further cellular and molecular studies to unravel the bases of resistance in this species.

Additional keywords: hypersensitive response, papilla, prepenetration resistance.
All cultivated forms of beet belong to the species Beta vulgaris sp. vulgaris L. During 18th century, beet became an established crop in mixed farm systems in Europe for animal and human feed (8). Since then, various types of beet are cultivated in nearly every country throughout Europe and in North America, Chile, Uruguay, China, the Middle East, North Africa, and the former Soviet Union (23) with a production of ca. 250 million tons (FAO, 2008). Today the most widely cultivated forms of Beta vulgaris are the "leaf type" spinach beet, the "root type" sugar beet, the fodder beet, and the garden beet (8).

Powdery mildew is a biotroph pathogen that seriously constrains crop production in many temperate regions. Erysiphe betae (Vañha) Weltz. is the causal agent of beet powdery mildew, a worldwide fungal disease resulting in looses of up to $30 \%$ (23). The disease is characterized by white dustlike mycelium that develops over the leaf surface. Heavily infected tissues develop chlorosis and suffer early senescence. Infection is especially damaging in areas with arid climates, for example in Mediterranean countries, the Middle East, and in California (22). The host range of $E$. betae includes all types of cultivated beets and related Beta species (1).

Despite the importance of legume and/or beet powdery mildew, most studies on powdery mildew have been carried out on the cereal-powdery mildew interaction $(4,12,13,29)$ and only a few on beet powdery mildew $(9,17)$. Establishment of functional biotrophy by powdery mildew can broadly be considered a two-stage process (27). The first depends upon the appressorial penetration peg penetrating the plant cuticle-epidermal cell wall barrier and then breaching the papilla that is deposited as a response to attempted penetration $(25,29)$. Failure of penetration, due to plant resistance associated with papilla formation and/or cell wall

Corresponding author: D. Rubiales; E-mail address: ge2ruozd@uco.es

doi:10.1094/PHYTO-99-4-0385

(c) 2009 The American Phytopathological Society strengthening, obviously prevents colony establishment. The second stage requires that upon entering the plant cell, the fungal penetration peg differentiates an haustorium without killing its host cell and, from it, absorbs nutrients to support colony growth $(25,29)$. Death of the invaded epidermal cell after penetration of the host wall/papilla barrier arrests haustorium development and again stops colony development. In some cases, after the fungus establishes a functional haustorium, posthaustorial resistance may delay growth of secondary hyphae, maturation of secondary appressoria, and therefore sporulation of the colony (19).

Screening for new sources of resistance is a valuable tool that ultimately may lead to the incorporation of the resistance traits into a cultivated genotype. Indeed, the need for higher levels of resistance has led to screening for new sources. In a recent screening program of 600 genotypes belonging to different Beta species, $5 \%$ genotypes showed powdery mildew resistance. Most resistant genotypes belonged to the species maritima, sexually compatible with cultivated beet, species vulgaris, but more divergent in its traits (1). Resistance has also been identified in leaf beets $(1,15)$, but little is known of the underlying resistance mechanisms and it has been only reported that most resistance appears to be expressed as a slow-mildewing phenotype (7). Knowledge of the mechanisms underlying resistance is important for breeding programs since the different resistance mechanisms have different effects in plant physiology and may affect plant performance and fitness in combination with other stresses (20) or they may also influence the durability of resistance. Thus, resistance mechanisms such as the hypersensitive response (HR) relying on major genes have been proven ephemeral compared with those resistance mechanisms controlled by complex genetics such as penetration resistance.

In the present work, we aimed to find new sources of resistance to beet powdery mildew in cultivated, leaf, and root type beet for use in breeding programs. In addition, we sought to characterize the underlying resistance mechanism/s for breeding purposes and as starting point for cellular and molecular studies that will further reveal the molecular bases of resistance. 


\section{MATERIALS AND METHODS}

Plant and pathogen materials. Seed of the 184 genotypes of B. vulgaris sp. vulgaris was obtained from L. Frese (Gene BankPlant Genetic Resources Collection, Braunschweig, Germany). Seeds were germinated in petri dishes with moistened filter papers in dark for $48 \mathrm{~h}$ in a growth chamber at $65 \%$ relative humidity and $20^{\circ} \mathrm{C}$. Then, seedlings were sowed in $125-\mathrm{ml}$ pots filled with peat/sand (3:1) and returned to the growth chamber under a photoperiod of 12-h light supplied with $250 \mu \mathrm{mol} \mathrm{m} \mathrm{m}^{-2} \mathrm{~s}^{-1}$ photon flux density supplied by high-output white fluorescent tubes for approximately 4 weeks. When plants had four expanded leaves, they were inoculated with E. betae, isolate CO07, collected on susceptible sugar beet plants in Córdoba, Spain. The isolate was maintained on susceptible leaf beet genotype 54867 . One day before inoculum was required, heavily infected plants were shaken to remove ageing conidia and ensure a supply of vigorous young spores.

Macroscopic assessment of symptom development following inoculation with $\boldsymbol{E}$. betae. In a first experiment, the whole collection was macroscopically assessed for disease severity to rule out those plants showing susceptibility from the histological studies.

For this screening, three plants of each genotype were assessed. When fully expanded, the fourth leaf (approximately 30 days after sowing) plants were inoculated with $E$. betae using a settling tower (16) to give about 30 conidia $\mathrm{mm}^{-2}$. Plants were maintained in the above-mentioned growth chamber for 16 days before assessment of the percentage of leaf area covered by powdery mildew. The susceptible fodder leaf genotype 54867 was used as control. Four genotypes showing less than $25 \%$ of leaves covered by powdery mildew were taken for further histological studies from each beet type, except from sugar beet from which only three genotypes were studied.

Microscopic observations of $E$. betae development and epidermal cell responses to attack. Inoculation, fixation, and clearing. Four plants of each genotype that had previously shown less than $25 \%$ mycelium covering the leaf were grown in randomized blocks during 30 days until the fourth-formed leaf was expanded. Then, the third-formed leaves were cut and placed (adaxial surface up) beneath the settling tower, with the petiole covered by moistened tissue paper. Then, they were inoculated with 30 conidia $\mathrm{mm}^{-2}$ and immediately returned to a flask with water inside the growth cabinet. At $42 \mathrm{~h}$ after inoculation, four leaves of the selected genotypes were fixed on pads moistened with acetic acid-ethanol (1:3, vol/vol) and cleared with lactoglycerol as described by Carver et al. (5) to avoid displacement of ungerminated conidia and loosely attached germlings.

Microscopy. To stain fungal structures and facilitate microscopy, a drop of Aniline blue in lactoglycerol $(0.1 \%)$ was placed on a coverslip and a cleared leaf segment was lowered onto the coverslip so that its inoculated surface met the stain. The coverslip was then inverted onto a microscope slide smeared with lactoglycerol to complete the mount. This procedure minimizes displacement of loosely attached germlings or ungerminated conidia (16). Observations were made with a Leica microscope fitted with differential interference contrast and incident fluorescence attachments. To avoid possible interactive effects, outcomes of fungal attack were only recorded when a single fungal appressorium was in contact with a host cell.

To assess success of penetration, on each replicate leaf 100 germlings with mature appressoria were examined. Some epidermal cells survived attack and resisted penetration by producing an effective papilla beneath the appressorium of the fungus. Note was taken of whether germlings had penetrated successfully to form a visible haustorium within the subtending epidermal cell or a papilla had stopped the fungal development. In cases where cells were penetrated, note was taken whether the penetrated epidermal cells died in response to attack following the HR. In these cases, cell cytoplasm was disorganized, and whole-cell autofluorescence visualized by incident fluorescence microscopy (blue exciter filter, max transmittance $400 \mathrm{~nm}$; dichroic mirror and barrier filter transmittance $>530 \mathrm{~nm}$ ) was evident throughout the cytoplasm and cell wall (28). Note was also taken of percentage of cells showing an early or late cell death: when no haustorium was visible inside the cell or an haustorium and/or small secondary hyphae could be seen, respectively. Germlings that successfully penetrated a cell, developed an haustorium and secondary hyphae in the absence of cell death were considered to have established a colony. In these, the number of hyphae was recorded to determine whether posthaustorial resistance mechanisms could limit the colony development.

For all characteristics, percentage data were calculated for each leaf replicate. For statistical analysis, percentages were transformed to arcsine square roots (transformed value $=180 / \Pi \times$ arcsine $[\sqrt{ }(\% / 100)])$ to normalize data and stabilize variances throughout the data range, and subjected to analysis of variance (ANOVA) using SPSS software 15.0, after which residual plots were inspected to confirm data conformed to normality. The significance of mean differences between each genotype against the control was evaluated by the two-sided Dunnett test. The significance of mean differences among genotypes was evaluated by the least significant difference at $P<0.01$, performed using GenStat 6.0 for Windows.

\section{RESULTS}

The macroscopic assessment of the beet collection showed that at time of evaluation genotypes presented no more than $60 \%$ of the leaf covered by mycelium with most of the genotypes showing between 25 and $35 \%$ of leaf covered. The group that showed higher resistance was the garden beet with most of the genotypes between 0 and $30 \%$ of symptoms and the most susceptible was the sugar beet. However, resistant genotypes were identified in all beet types studied.

A further histological study revealed the resistance mechanisms underlying resistance. In some of the genotypes, resistance mechanisms that hampered fungal development at several developmental stages accounted for the low level of macroscopic symptoms observed. This was the case for leaf beet type genotypes (genotypes 33461, 62714, 6223, and 49860). In other cases, resistance was achieved by affecting one of the main fungal developmental stages necessary to establish the biotrophy, such as epidermal cell penetration, haustorium development, and hyphae growth. Three of the selected genotypes (895, 26527, and 49858) tended to show higher values in the different parameters assessed, but none of these genotypes differed significantly from the control. However, they still showed low level of macroscopic symptoms, probably due to the effect of all of them together.

Penetration resistance was significantly affected by the genotype (ANOVA, $P<0.001$ ). Most genotypes (Table 1) showed a high penetration resistance with a significant lower number of cells penetrated by the fungal appressorium compared with the susceptible control. The garden beet genotype 6223, with $98.8 \%$ cells resistant to penetration attempts, showed the highest penetration resistance rate. Indeed, this genotype showed most interesting as penetrated cell limited further fungal development by the death of the penetrated cell, hence avoiding the establishment of any colony. Frequently, though not invariably, penetration resistance was associated with a localized yellow-green autofluorescence that was visualized by incident fluorescence microscopy (Fig. 1A). Appressorium of E. betae resembled that of E. pisi with several lobes around the appressorium (Fig. 1) and differed from that of cereal powdery mildews (Blumeria graminis) with a highly ordered disposition of appressorial lobes from which the fungus attempts to penetrate the epidermal cell. 
Several genotypes limited fungal development through programmed death of the attacked cells. In these, i.e., the fodder beat 33461 , the garden beat 65479 , the leaf beet 45521 , or the sugar beet 49860 , cell cytoplasm was disorganized, and whole-cell autofluorescence was evident throughout the cytoplasm and cell wall (Fig. 1B and C). In all of the above-mentioned genotypes, cell death was very fast and no haustorium or hyphae could be recorded (Fig. 1B). However, in other genotypes, such as 62714, 1284, 6353, and 62709 , the triggering of programmed cell death was late or execution was slow and an haustorium or small secondary hyphae could be seen associated to the germling (Fig. 1C). One of the genotypes, the leaf beet 62709 , showed a significantly higher proportion of both early and late cell death compared with the susceptible control 54867. The effect of genotype was significant for both parameters (ANOVA, $P<0.001$ and 0.004 , respectively).

The penetration resistance and the cell death observed in many of the genotypes contributed to significantly reduce the number of established colonies. However, even when a germling formed a functional haustorium and established a colony (Fig. 1D and D'), further resistance, posthaustorial mechanisms, limited the growth of the colony in several genotypes (ANOVA, $P<0.000$ ). At time of fixation, the number of hyphae of established colonies ranged between one and seven, and in the susceptible control, approximately $50 \%$ of the germlings had four or more hyphae. The percentage of established colonies showing two or less secondary hyphae was recorded to determine whether posthaustorial mechanisms could contribute to the low visible symptoms observed. In the garden beet genotype 45534, the percentage of germlings with less than two secondary hyphae was the only significant parameter different from the susceptible control. The leaf beet genotype 62709 showed the highest percentage of posthaustorial resistance as none of the established colonies had more than two secondary hyphae.

Interestingly, several genotypes showed a combination of two $(33461,6223,65479$, and 49860$)$ or several $(62714,45521,1284$, 6353, and 62709) resistance mechanisms. The most interesting genotype in this case was the leaf beet 62709 since it showed a high level of prepenetration resistance $(89.1 \%)$, a high proportion of early and late cell death (67.0 and $21.4 \%$, respectively), and a significant high frequency of colonies with less than two hyphae compared with the control. This combination of mechanisms was particularly observed in the leaf beet genotypes, although it was also found in some of the other types.

\section{DISCUSSION}

Different resistance mechanisms may prevent plant infection by powdery mildew at different fungal developmental stages. We did not find differences in germination in most of the genotypes, albeit genotype 49862 showed a significant higher germination rate. Normally conidia do not germinate when attached to the conidiophore, within the mother colony, but do germinate rapidly after separation. This suggests that inhibitory processes suppress germination when spores are attached and the separation to the conidiophore may be the only stimulus necessary to induce germination $(3,4)$. One fact that supports this hypothesis is that in several cases conidia of E. pisi as well as of Blumeria graminis, the pea and cereal powdery mildew, respectively, may germinate in a simulated airborne state on spider's suspension thread (3). Our results agree with this hypothesis.

Attacked cells may prevent fungal penetration by forming cell wall appositions named papillae (26). In this work, we observed a high penetration resistance in most selected genotypes, which offers opportunities for breeding for this trait. The garden beet type 6223 showed the highest penetration resistance. Although the molecular bases of penetration resistance are not fully understood yet, this mechanism includes complex processes and genetic requirements (review in 10). This makes this form of resistance more difficult to be overcome by new races of pathogens than others such as the HR based in a gene-for-gene interaction. We observed in all genotypes fluorescence associated with several of the attempted penetration sites and especially in those sites showing penetration resistance. It has been reported that autofluorescent phenolic compounds are normally present within the papilla strengthening it (6), though fluorescence is more often observed and brighter in cereal than in other plant-powdery mildew interactions (29).

In addition to penetration resistance, early and late HR due to the interaction between resistance $(R)$ and avirulence $(a v r)$ genes

TABLE 1. Microscopic assessment of Erysiphe betae development and leaf epidermal cell responses of Beta vulgaris genotypes

\begin{tabular}{|c|c|c|c|c|c|c|c|c|c|}
\hline \multirow[b]{2}{*}{ Beet type } & \multirow[b]{2}{*}{ Genotype } & \multirow[b]{2}{*}{ Germination } & \multirow{2}{*}{$\begin{array}{l}\text { Penetration } \\
\text { resistance }\end{array}$} & \multicolumn{3}{|c|}{ Penetrated cells } & \multirow[b]{2}{*}{ Total } & \multirow{2}{*}{$\begin{array}{l}\text { Est. colonies } \\
\leq 2 \text { hyphae }\end{array}$} & \multirow{2}{*}{$\begin{array}{l}\text { Disease } \\
\text { severity }\end{array}$} \\
\hline & & & & Early CD & Late CD & Est. colonies & & & \\
\hline \multirow[t]{5}{*}{ Fodder } & 54867 & $65.9 \pm 0.9$ & $51.1 \pm 5.5$ & $31.3 \pm 8.0$ & $3.2 \pm 0.6$ & $65.5 \pm 8.2$ & $48.9 \pm 5.5$ & $27.1 \pm 3.8$ & $40.0 \pm 3.3$ \\
\hline & 895 & $64.9 \pm 2.8^{\mathrm{ns}}$ & $69.1 \pm 5.9^{\mathrm{ns}}$ & $61.1 \pm 6.7^{\mathrm{ns}}$ & $2.7 \pm 0.6^{\mathrm{ns}}$ & $36.2 \pm 6.8^{\mathrm{ns}}$ & $30.9 \pm 5.9^{\mathrm{ns}}$ & $62.0 \pm 14.6^{\mathrm{ns}}$ & $4.5 \pm 2.0^{* * * *}$ \\
\hline & 33461 & $64.6 \pm 6.0^{\mathrm{ns}}$ & $81.3 \pm 14.6^{*}$ & $81.5 \pm 6.0^{* *}$ & $4.6 \pm 1.9^{\mathrm{ns}}$ & $13.9 \pm 5.0^{* * * *}$ & $18.7 \pm 14.6^{*}$ & $55.0 \pm 19.0^{\mathrm{ns}}$ & $20.0 \pm 2.6^{*}$ \\
\hline & 51790 & $66.0 \pm 6.6^{\mathrm{ns}}$ & $84.1 \pm 4.2^{* *}$ & $58.2 \pm 6.8^{\mathrm{ns}}$ & $10.6 \pm 1.1^{\mathrm{ns}}$ & $31.2 \pm 6.7^{*}$ & $15.9 \pm 4.2^{*}$ & $66.2 \pm 9.0^{\mathrm{ns}}$ & $8.7 \pm 2.1^{* * * *}$ \\
\hline & 62714 & $59.2 \pm 3.1^{\mathrm{ns}}$ & $80.7 \pm 2.7^{*}$ & $56.3 \pm 4.5^{\mathrm{ns}}$ & $21.3 \pm 10.2^{*}$ & $22.4 \pm 6.8^{* *}$ & $19.3 \pm 2.7^{*}$ & $94.3 \pm 3.8^{* * * *}$ & $0.7 \pm 0.7^{\text {**** }}$ \\
\hline \multirow[t]{4}{*}{ Garden } & 6223 & $67.4 \pm 5.2^{\mathrm{ns}}$ & $98.8 \pm 0.8^{* * *}$ & $85.2 \pm 9.3^{* * * *}$ & $14.8 \pm 9.3^{\mathrm{ns}}$ & $0.0 \pm 0.0^{* * * *}$ & $1.2 \pm 0.8^{* * *}$ & $\ldots$ & $0.0 \pm 0.0^{* * * *}$ \\
\hline & 26527 & $67.1 \pm 3.6^{\mathrm{ns}}$ & $60.5 \pm 9.7^{\mathrm{ns}}$ & $43.1 \pm 10.2^{\mathrm{ns}}$ & $8.1 \pm 2.8^{\text {ns }}$ & $48.8 \pm 10.4^{\mathrm{ns}}$ & $39.5 \pm 9.7^{\mathrm{ns}}$ & $65.0 \pm 9.4^{\mathrm{ns}}$ & $10.0 \pm 3.7^{* *}$ \\
\hline & 45534 & $70.0 \pm 9.4^{\mathrm{ns}}$ & $66.0 \pm 3.6^{\mathrm{ns}}$ & $39.9 \pm 3.9^{\mathrm{ns}}$ & $9.7 \pm 4.2^{\mathrm{ns}}$ & $50.4 \pm 3.5^{\mathrm{ns}}$ & $34.0 \pm 3.6^{\mathrm{ns}}$ & $83.4 \pm 8.4^{* *}$ & $1.8 \pm 1.2^{* * * *}$ \\
\hline & 65479 & $69.1 \pm 1.3^{\mathrm{ns}}$ & $81.8 \pm 6.0^{*}$ & $74.1 \pm 7.3^{* *}$ & $4.3 \pm 1.5^{\mathrm{ns}}$ & $21.5 \pm 6.0^{* *}$ & $18.2 \pm 6.0^{*}$ & $64.5 \pm 6.6^{\mathrm{ns}}$ & $5.0 \pm 0.0^{* * * *}$ \\
\hline \multirow[t]{4}{*}{ Leaf } & 1284 & $67.9 \pm 4.1^{\mathrm{ns}}$ & $64.7 \pm 11.0^{\mathrm{ns}}$ & $46.7 \pm 12.9^{\mathrm{ns}}$ & $30.3 \pm 13.9^{* *}$ & $23.0 \pm 5.6^{* *}$ & $35.3 \pm 11.0^{\mathrm{ns}}$ & $71.6 \pm 17.9^{*}$ & $21.8 \pm 3.5^{*}$ \\
\hline & 6353 & $68.4 \pm 0.6^{\mathrm{ns}}$ & $85.3 \pm 4.9^{*}$ & $55.8 \pm 8.3^{\mathrm{ns}}$ & $22.2 \pm 1.6^{*}$ & $21.9 \pm 6.8^{* *}$ & $14.7 \pm 4.9^{*}$ & $89.7 \pm 10.3^{* *}$ & $1.2 \pm 1.2^{* * * *}$ \\
\hline & 45521 & $71.0 \pm 3.5^{\mathrm{ns}}$ & $88.5 \pm 5.4^{* * *}$ & $73.9 \pm 10.4^{* *}$ & $5.4 \pm 1.3^{\mathrm{ns}}$ & $20.7 \pm 9.3^{* *}$ & $11.5 \pm 5.4^{* *}$ & $86.4 \pm 10.8^{* * *}$ & $2.8 \pm 4.4^{* * * *}$ \\
\hline & 62709 & $68.7 \pm 2.9^{\mathrm{ns}}$ & $89.1 \pm 1.5^{* *}$ & $67.0 \pm 6.4^{*}$ & $21.4 \pm 7.0^{*}$ & $11.6 \pm 4.1^{* * * *}$ & $10.9 \pm 1.5^{* *}$ & $100.0 \pm 0.0^{* * * *}$ & $4.1 \pm 3.3^{\text {*** }}$ \\
\hline \multirow[t]{3}{*}{ Sugar } & 49858 & $70.4 \pm 4.2^{\mathrm{ns}}$ & $71.7 \pm 6.5^{\mathrm{ns}}$ & $47.0 \pm 8.5^{\mathrm{ns}}$ & $7.6 \pm 1.5^{\mathrm{ns}}$ & $45.4 \pm 7.9^{\mathrm{ns}}$ & $28.3 \pm 6.5^{\mathrm{ns}}$ & $62.9 \pm 10.1^{\mathrm{ns}}$ & $0.0 \pm 0.0^{* * * *}$ \\
\hline & 49860 & $68.2 \pm 3.9^{\mathrm{ns}}$ & $90.3 \pm 2.0^{* * *}$ & $70.7 \pm 6.0^{*}$ & $4.0 \pm 2.2^{\mathrm{ns}}$ & $25.3 \pm 4.0^{* *}$ & $9.7 \pm 2.0^{* *}$ & $62.2 \pm 7.2^{\mathrm{ns}}$ & $24.0 \pm 6.8^{*}$ \\
\hline & 49862 & $82.6 \pm 2.9^{*}$ & $76.6 \pm 5.9^{*}$ & $54.0 \pm 12.8^{\mathrm{ns}}$ & $6.1 \pm 1.5^{\mathrm{ns}}$ & $39.9 \pm 13.6^{\mathrm{ns}}$ & $23.4 \pm 5.9^{\mathrm{ns}}$ & $37.2 \pm 4.8^{\mathrm{ns}}$ & $23.3 \pm 6.1^{*}$ \\
\hline LSD & & 15.8 & 28.4 & 34.1 & 15.8 & 33.7 & 28.4 & 42.7 & 15.7 \\
\hline
\end{tabular}

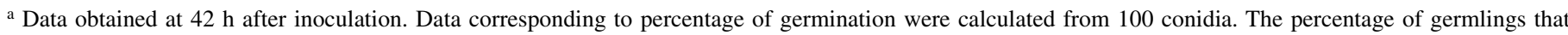
reached different developmental stages (passing from one stage to the next) was assessed from at least 100 germinated spores in each of four replicate leaves. The values represent the percentage of conidia that formed an appressorium but did not penetrate epidermal cell (penetration resistance) or those able to penetrate the cells (total penetrated). From those germlings that penetrated the epidermal cell, the percentage of them that elicited cell death before (early CD) or after (late CD) haustorium and/or secondary hyphae could be visible and those that formed an established colony were assessed. The percentage of established colonies that had two or less secondary hypha was also assessed. Analysis of variance was applied to transformed replicate data, and the genotypes and the susceptible control 54867 were assessed by Dunnett's test. ${ }^{*},{ }^{* *}$, and ${ }^{* * *}$ indicate significant differences at $P<0.05,0.01$, and 0.001 , respectively; ${ }^{*}$ indicates no significant difference when comparing each genotype with the control. Least significant difference (LSD) value $(P<0.01)$ is provided for comparison among genotypes. 
(review in 18) actively contributed to resistance in several genotypes. Thus, several of the studied genotypes such as 33461, $6223,65479,45521$, and 49860 elicited an early cell death, that is, before haustoria and/or secondary hyphae could be visible. Genotypes 62714, 1284, and 6353 were characterized by a late cell death, and in genotype 62709 , both early and late cell death could be observed. Tosa and Shishiyama (26) and Johnson et al. (11) concluded that this form of resistance operates when the papilla barrier is overcome by the fungus. Therefore, genotypes with high penetration resistance in addition to cell death, such as $33461,6223,65479,45521$, or 49860 , might be highly useful as they assure a more effective defense.

When the plant fails to prevent fungal penetration and to trigger cell death, the fungus develops the haustorium establishing the biotrophy. Susceptible genotype 54867 formed $65 \%$ of established colonies, indicating the functionality of the haustoria that allowed the hypha growth. Several genotypes showed a similar rate of established colonies, i.e., 895, 26527, 45534, 49858, and 49862. Interestingly, several genotypes such as fodder beet 62714 , garden beet 45534 , or leaf beet 62709 independently of the rate of established colonies showed a decrease in the size of the colony. After haustorium formation, the pathogen is able to control host cell processes impairing defensive responses while preserving or enhancing the metabolic processes necessary to fungal nutrition (14). Very little is known about the molecular bases of haustorium-host cell interaction and therefore about posthaustorial resistance. However, it has been reported that resistance mechanisms acting after haustorium formation lead to a restriction of nutrient flow to the pathogen, restricting the number of secondary, tertiary, etc. haustoria, colony size, and number of conidiophores (2). The reduced colony size observed in 62714 ,
45534, and 62709 might be explained by these posthaustorial resistance mechanisms.

The characterization of the resistance mechanisms operating in the different types of beets presented is of high importance. First, the use of a genotype with combined resistance mechanisms that stop fungal growth at several stages may prove more durable and difficult to be overcome than resistance based on a single mechanism and even more when this mechanism is governed by a single gene as occur in the HR. In fact, it has been suggested that under field conditions HR may be relatively easily overcome by the evolving pathogen. Thus, coupling different resistance mechanisms that are under genetically complex control, and affecting different phases of plant-pathogen interaction (e.g., papilla-based penetration resistance together with death of attacked cells and/or posthaustorial mechanisms) would present a series of barriers to pathogenesis. Such resistance should prove more durable than single gene controlled race-specific resistances that although easily manipulated in plant breeding programs have repeatedly proved ephemeral. Interestingly, we found genotypes showing different resistance mechanisms impairing fungal growth at several stages in most of the beet types such as the fodder beet 62714 , the garden beet 65479 , the leaf beet 62709 , and the sugar beet 49860 .

In addition, the knowledge of the mechanisms underlying resistance may be useful to limit the energetic cost or to avoid adverse physiological consequences of resistance processes. For instance, HR has been associated with an energetic cost and a dysfunction of stomatal activity that have not been associated to papilla formation $(21,24)$. This is an additional advantage for the use of penetration-resistant genotypes such as 51790 and 49862 in plant breeding.
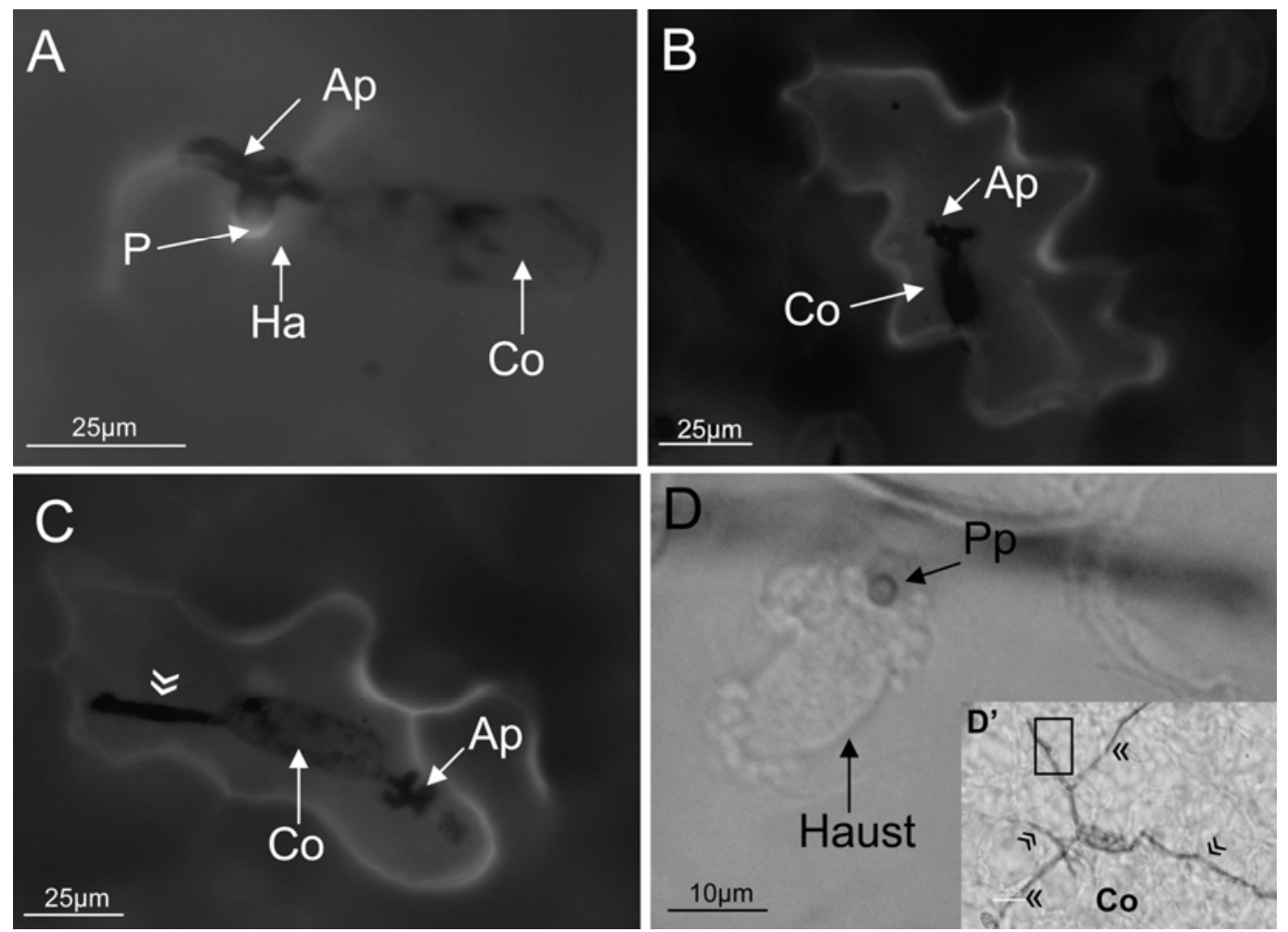

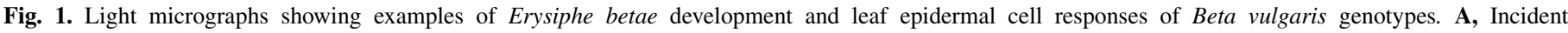

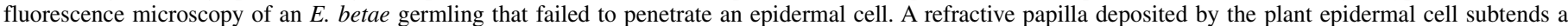

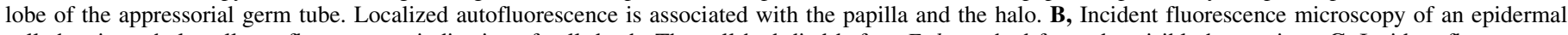

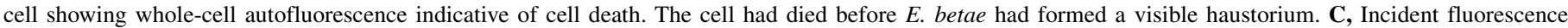

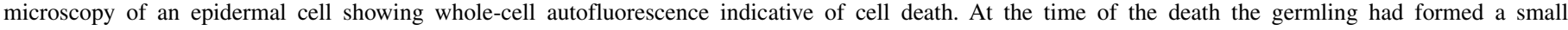

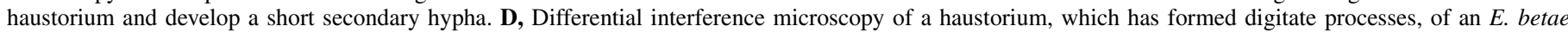

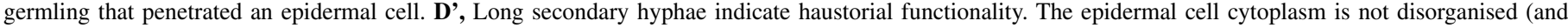

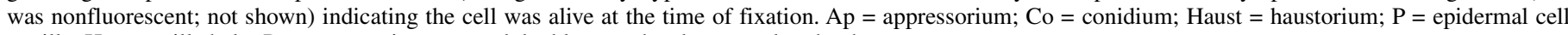
papilla; $\mathrm{Ha}=$ papilla halo; $\mathrm{Pp}=$ penetration peg; and double arrowhead $=$ secondary hyphae. 


\section{LITERATURE CITED}

1. Asher, M. J. C., Luterbacher, M. C., and Frese, L. 2001. Wild Beta species as a source of resistance to sugar-beet pests and diseases. Int. Sugar J. 103:447-451.

2. Carver, T. L. W., and Carr, A. J. H. 1978. Effects of host resistance on development of haustoria and colonies of oat mildew. Ann. Appl. Biol. 88:171-178.

3. Carver, T. L. W., and Ingerson, S. M. 1987. Responses of Erysiphe graminis germlings to contact with artificial and host surfaces. Physiol. Mol. Plant Pathol. 30:359-372.

4. Carver, T. L. W., Kunoh, H., Thomas, B. J., and Nicholson, R. L. 1999. Release and visualization of the extracellular matrix of conidia of Blumeria graminis. Mycol. Res. 103:547-560.

5. Carver, T. L. W., Robbins, M. P., and Zeyen, R. J. 1991. Effects of 2 PAL inhibitors on the susceptibility and localized autofluorescent host-cell responses of oat leaves attacked by Erysiphe graminis DC. Physiol. Mol. Plant Pathol. 39:269-287.

6. Cassab, G. I. 1998. Plant cell wall proteins. Ann. Rev. Plant Physiol. Plant Mol. Biol. 49:281-309.

7. Francis, S. 2002. Sugar-beet powdery mildew (Erysiphe betae). Mol. Plant Pathol. 3:119-124.

8. Hall, R. D., Pedersen, C., and Krens, F. A. 1994. Regeneration of plants from protoplasts of Beta vulgaris (sugar beet). Pages 16-37 in: Biotechnology in Agriculture and Forestry. Plant Protoplast and Genetic Engineering. Y. P. S. Bajaj, ed. Springer-Verlag, Berlin.

9. Hamacher, J. 1987. The haustorial complex of Erysiphe betae (Vanha) Weltzien. J. Phytopathol. 118:289-300.

10. Huckelhoven, R. 2007. Cell wall-associated mechanisms of disease resistance and susceptibility. Ann. Rev. Phytopathol. 45:101-127.

11. Johnson, L. E. B., Bushnell, W. R., and Zeyen, R. J. 1982. Defense patterns in non-host higher-plant species against 2 powdery mildew fungi. 1. Monocotyledonous species. Can. J. Bot. 60:1068-1083.

12. Koga, H., Mayama, S., and Shishiyama, J. 1980. Correlation between the deposition of fluorescent compounds in papillae and resistance in barley against Erysiphe graminis hordei. Can. J. Bot. 58:536-541.

13. Kruger, W. M., Carver, T. L. W., and Zeyen, R. J. 2002. Effects of inhibiting phenolic biosynthesis on penetration resistance of barley isolines containing seven powdery mildew resistance genes or alleles. Physiol. Mol. Plant Pathol. 61:41-51.

14. Leckie, C. P., Callow, J. A., and Green, J. R. 1995. Reorganization of the endoplasmic reticulum in pea leaf epidermal cells infected by the powdery mildew fungus Erysiphe pisi. New Phytol. 131:211-221.

15. Luterbacher, M. C., Smith, J. M., Asher, M. J. C., and Frese, L. 2000. Disease resistance in collections of Beta species. J. Sugar Beet Res. $37: 39-47$.
16. Lyngkjær, M. F., and Carver, T. L. W. 1999. Induced accessibility and inaccessibility to Blumeria graminis f. sp. hordei in barley epidermal cells attacked by a compatible isolate. Physiol. Mol. Plant Pathol. 55:151-162.

17. Mukhopadhyay, A. N., and Russell, G. E. 1979. Light and scanning microscopy of sugar beet powdery mildew. Trans. Brit. Mycol. Soc. 72:316-319.

18. Mur, L. A. J., Kenton, P., Lloyd, A. J., Ougham, H., and Prats, E. 2008. The hypersensitive response; The centenary is upon us but how much do we know? J. Exp. Bot. 59:501-520.

19. Niks, R. E., and Rubiales, D. 2002. Potentially durable resistance mechanisms in plants to specialised fungal pathogens. Euphytica 124:201-216.

20. Prats, E., Carver, T. L. W., Gay, A., and Mur, L. A. J. 2007. Enemy at the gates: Interaction-specific stomatal responses to pathogenic challenge. Plant Signal. Behav. 2:275-277.

21. Prats, E., Gay, A. P., Mur, L. A. J., Thomas, B. J., and Carver, T. L. W. 2006. Stomatal lock-open, a consequence of epidermal cell death, follows transient suppression of stomatal opening in barley attacked by Blumeria graminis. J. Exp. Bot. 57:2211-2226.

22. Ruppel, E. G. 1995. Powdery mildew. Pages 13-15 in: Compendium of Beet Diseases and Insects. E. D. Whitney and J. E. Duffus, eds. American Phytopathological Society, St. Paul, MN.

23. Scott, R. K., and Jaggard, K. W. 1993. Crop physiology and agronomy. In: The Sugar Beet Crop. D. A. Cooke and R. K. Scott, eds. Chapman and Hall, London, UK.

24. Smedegaard-Petersen, V., and Stølen, O. 1981. Effect of energy requiring defense reactions on yield and grain quality in a powdery mildew resistant barley cultivar. Phytopathology 71:396-399.

25. Smith, P. H., Foster, E. M., Boyd, L. A., and Brown, J. K. M. 1996. The early development of Erysiphe pisi on Pisum sativum L. Plant Pathol. 45:302-309.

26. Tosa, Y., and Shishiyama, J. 1984. Defense reactions of barley cultivars to an inappropriate forma specialis of the powdery mildew fungus of gramineous plants. Can. J. Bot. 62:2114-2117.

27. Vanacker, H., Carver, T. L. W., and Foyer, C. H. 2000. Early $\mathrm{H}_{2} \mathrm{O}_{2}$ accumulation in mesophyll cells leads to induction of glutathione during the hyper-sensitive response in the barley-powdery mildew interaction. Plant Physiol. 123:1289-1300.

28. Zeyen, R. J., Bushnell, W. R., Carver, T. L. W., Robbins, M. P., Clark, T. A., Boyles, D. A., and Vance, C. P. 1995. Inhibiting phenylalanine ammonia-lyase and cinnamyl-alcohol dehydrogenase suppresses Mla1 (HR) but not Mlo5 (non-HR) barley powdery mildew resistances. Physiol. Mol. Plant Pathol. 47:119-140.

29. Zeyen, R. J., Carver, T. L. W., and Lyngkjaer, M. F. 2002. Epidermal cell papillae. Pages 107-125 in: Powdery Mildews: A Comprehensive Treatise. R. R. Belanger, W. R. Bushnell, A. J. Dik, and T. L. W. Carver, eds. American Phytopathological Society, St. Paul, MN. 